\title{
As mulheres que os homens deixam escapar - literatura de língua castelhana escrita por homens (1880-1920)
}

\author{
Demystifying the Female Body in \\ Hispanic Male Authors, 1880-1920 \\ - Overcoming the Virgin/Prostitute \\ Dichotomy.
}

COHEN, Daria.

Queenston, Ontario: The Edwin Mellen Press, 2008. $111 \mathrm{p}$.

O estudo de Daria Cohen oferece uma análise rara do tratamento do corpo da mulher na literatura como um campo de "batalha ideológica" em selecionados contos de língua castelhana escritos por Rubén Darío, Manuel Gutiérrez Nájera, Manuel Díaz Rodríguez, Azorín (José Martínez Ruiz), Miguel de Unamuno e Ramón del Valle-Inclán no período conhecido como fin-de-siècle. O trabalho apresenta uma introdução, quatro capítulos e conclusão.

$\mathrm{Na}$ introdução, Cohen explicita sua base teórica. Expõe o recorte do período modernista na América Latina e na Espanha, ao considerar escritores latino-americanos e espanhóis conjuntamente, optando com acerto por uma periodi- zação que conflui o modernismo latino-americano à Geração de 1898 espanhola, assim propondo a modernidade como um tempo de inovações que perpassam o Ocidente e não se atêm a localidades, como sugerem os teóricos Richard Cardwell, Federico de Onís, Ivan Schulman, Evelyn Picon Garfield, entre outros. Também aponta as teóricas feministas que a informam em sua análise, como Susan Suleiman, Elaine Showalter, Gilbert and Gubar, Rita Felski, entre outras. Em seu estudo, Cohen perscruta "tipos diferentes de corpos de mulher" dentro das relações de poder em que são encaixados pelos escritores. Distingue seu estudo em relação ao de Consuelo Arias (Representations of the Feminine in Modernismo: The Figure of the Exotic Woman. Em português, Representações do feminino no modernismo: a figura da mulher exótica). Citando Elisabeth Grosz (Volatile Bodies. Em português, Corpos voláteis), Cohen oferece uma boa discussão sobre o que denomina "feminismo corporal", segundo o qual o corpo é tomado como um "terreno de contestação" interpenetrado, nem como vítima nem como agressor, por instâncias várias da vida social. O corpo, assim compreendido, seria a base da subjetividade moderna, como um "local de contradições", segundo conceitos de Anthony Casdardi (The Subject of Modernity. Em portu- 
guês, O sujeito da modernidade), Meile Steele (Theorizing Textual Subjects, em português Teorizando sujeitos textuais) e Catherine Belsey (Critical Theory. Em português, Teoria crítica). Cohen se utiliza também da contribuição de "The Body of the Condemned" (em português, "O corpo do condenado") em Vigiar e punir, de Michel Foucault, completando a noção do corpo como ponto a partir do qual "resistência e agência estratégicas" são possíveis, sendo este o local no qual "choques de gênero, poder e subjetividade" ocorrem. Os capítulos apresentam diferentes caracterizações das mulheres as manobras retóricas dos escritores para dar vazão às suas ansiedades, segundo Cohen, diante dos anseios da nova mulher que surgia.

O corpo como "O artefato sensual" é tratado no Capítulo 1. Cohen mostra a erotização do corpo da mulher por Rubén Darío (Nicarágua, 1867-1916), segundo uma estética, de fato, parnasiana, em "El rubí" - como objeto para o desfrute do olhar masculino. Para a autora, Darío cria uma aura de mistério que cultiva a alteridade, ao mesmo tempo enaltecendo e desfigurando o corpo da mulher. Assinalando a linguagem marcada por indícios de gênero, através da qual o artífice é o masculino e o material a ser modelado, o feminino, Cohen demonstra o significado subjacente ao texto como a vitória da criatividade ativa do homem sobre a matéria feminina inerte, como material bruto - reconfirmando a antiga dicotomia segundo a qual o masculino, com sua capacidade de idealização, não apenas cria sobre o corpo da mulher, mas desse modo pode controlá-lo. Mas "El rubí", ao mostrar o corpo da mulher com suas fruições próprias, tentando ademais libertar-se, demonstra uma agência não usual à época, confirmando a visão da autora de que um novo sujeito feminino moderno emerge.

No Capítulo 2, o corpo feminino é "A moldura artística" com que a literatura modernista objetificou esteticamente a presença da mulher como réplica retórica e metafórica da feitura do texto ele mesmo. Cohen sugere que, nesse sentido, o corpo da mulher como moldura reflete "os vários níveis das noções de limite e produção artística". Seguindo as sugestões de Helena Michie (The Flesh Made Word. Em português, $A$ carne feita palavra), Cohen mostra como o corpo das mulheres procura se desvencilhar dos enquadramentos nos quais os escritores querem prendê-las. Em "Rosa, lirio y clavel", de Azorín (Espanha, 1873-1967), um jogo da relação entre os gêneros emoldura a mulher para 0 olhar masculino, num texto modernista por excelência, dada a preocupação expressa (de l'art pour l'art) do escritor com o fazer literário. Na cena descrita por um velho viajante, de ambientação à la prérafaelitas, três mulheres se movimentam e seus corpos são detalhadamente descritos por sua sensualidade. Segundo a autora, ao descrevê-las e emoldurá-las, o escritor as "enquadra" também no sentido jurídico de que as detém para averiguação, ou seja, critica-as e julga-as. Ao transformá-las em flores que acompanham outros personagens mórbidos da história, o enquadramento seguinte mostra que a sensualidade e a vitalidade das mulheres são tornadas inanimadas, segundo a autora, como uma forma de sublimar o estranhamento do próprio escritor diante de um mundo que se transformava (e o assombrava) radicalmente. No conto, "La venganza de Milord", de Manuel Gutiérrez Nájera (México, 1859-1895), mistério e intriga são mapeados nos corpos femininos. O narrador descreve a história de várias mulheres: Clara, a mulher que não amava; a segunda, a mulher boneca, sem vitalidade; a terceira, uma surreal mulher sem corpo cuja função obscura é aprisionar esposas; e, finalmente, Alícia, a mulher compelida a trair o marido para enfim terminar petrificada como a protagonista de $A$ bela adormecida. No entanto, sem o beijo final que the restaurasse a vida, como sugere Cohen, Alícia termina como um simples cadáver. Segundo a autora, esses enquadramentos das persona-gens demonstram o temor da sociedade expressa pelo escritor quanto à possibilidade da autonomia da mulher que se insinuava. No último conto analisado no capítulo, "La muerte de la emperatriz de la China", de Darío, Cohen mostra que a propensão do escritor para descrever como joia a mulher Suzette e como um estojo a sala em que se encontra evidencia o que Elaine Showalter denomina "The Case of Women". Em português, "O caso da mulher" (em inglês, o vocábulo "case" significa tanto "caso" como "estojo", "caixa"). Com isso, Showalter atenta para o fato de que a mulher se tornou, na época, um caso a ser analisado, como se fosse a caixa de Pandora, cheia de mistérios e perigos. Cohen nota, contudo, que Darío neste texto rompe com o padrão do texto anterior quando permite que sua protagonista destrua a imagem da imperatriz chinesa que o marido idolatrava em seu estúdio, dizendo, ao fazêlo, estar vingada. Para a autora, desse modo, Suzette "destrói o ícone exótico" que a espelha e, assim, demonstra "o sujeito feminino que astutamente resiste à opressão da sociedade".

Os enquadramentos estéticos assinalados anteriormente, segundo Cohen, levam ao que analisa no Capítulo 3 , ou seja, ao desvaneci- 
mento da mulher, como sugere o título "A presença apagada", "em resposta à nascente subjetividade da mulher moderna", já que os escritores com frequência se referem à morte da sensualidade feminina, exibindo um temor em relação à sua expressão. Consequentemente, Cohen detecta uma associação insistente entre o "corpo da mulher e a morte" como forma de aniquilação de seu poder. Cohen observa, no entanto, que há uma duplicidade nos textos, ou seja, uma tentativa de apagamento da mulher tão renitente como a emergência da agência feminina, mesmo que momentânea, em "cambiantes posições subjetivas" - ainda que a subjugação da mulher prevaleça, enfim. Em "Rosarito" e "Mi hermana Antonia", Ramón del Valle-Inclán (Galícia, 1866-1936) exemplifica o apagamento da mulher "nas mãos do homem moderno". A história da tímida e sexualmente inocente Antonia, que, seduzida por um estudante "de olhos de tigre", fenece, traz novamente uma atmosfera tétrica que trata da morte do corpo da mulher de modo a restituir a moralidade social. Também Rosarito, descrita com uma sensualidade ambivalente de anjo e prostituta ("trágica e madalênica") será seduzida e, enfim, morta pelo sedutor. Cohen compreende que ao matá-la, como já foi dito, o escritor procura extinguir o erotismo que aos poucos faz emergir a subjetividade da mulher moderna. Em "Cuento Rojo", de Manuel Díaz Rodríguez (Venezuela, 1871-1927), a autora apresenta uma luta entre o masculino e o feminino no contexto cultural moderno. Aqui o misógino protagonista Renzi, como ocorre com o mito de Don Juan, torna suas conquistas em "bonecas inanimadas" até encontrar Irma, uma mulher que não sucumbe aos seus ardis. Com um tapa no rosto de Irma, Renzi responde à indiferença da mulher, que, logo em seguida, como uma "selvagem voluptuosa", beija-o com os lábios ensanguentados. O narrador, nota Cohen, assinala a reação da mulher como algo novo a complicar o relacionamento entre amantes naquele tempo. Até aqui, Cohen conclui que a batalha entre os sexos ainda relega a mulher ao enquadramento do homem - seu temor da incipiente agência da mulher provoca a violência e o consequente apagamento dela.

Com o conto "Soledad", de Miguel de Unamuno (Espanha, 1864-1936), Cohen inicia o Capítulo 4 no qual seu estudo culmina, enfim, com "A desmistificação do corpo da mulher". Aqui se sobressai a mulher cujo modo de vida é satisfatório para si mesma. Amparo, uma mulher cujo marido é omisso e ausente, antes de morrer logo após ter uma filha, exige do marido que a nomeie Soledad, nome que definirá seu caráter, já que não pode contar com nenhum dos homens com quem se relaciona - pai, irmão ou amante. Ao aceitar essa decepção fundamental, para Cohen, dedicando-se à leitura de livros, Soledad viabiliza uma vida independente para si mesma. A sugestão de que lia também livros eróticos suscita a ideia de que sua autonomia se estende à sua própria sexualidade. Cohen aponta que, desse modo, Soledad transcende o estereótipo da solteirona solitária, sem par (the odd woman), um dos tipos sociais que suscitaram a questão da mulher à época. Os contos "La caperucita color de rosa" e "La ultima hada", de Manuel Gutiérrez Nájera, que Cohen nos mostra, desconstroem tanto os mitos da ingenuidade da Chapeuzinho vermelho como o da magia das fadas. No primeiro caso, encontramos uma Chapeuzinho que ludibria a todos e planeja passo a passo um casamento vantajoso. A fada, por seu turno, é posta de lado pela personagem Pensamento, que, dispensando os encantamentos da outra, faz suas próprias escoIhas. Em "La venganza de Milady", do mesmo autor, não só Milady retribui Milord com infidelidades, mas, em última instância, o trai com a própria amante do marido. Para Cohen, como é evidente, não apenas a mulher toma a frente em defesa própria, mas o faz demonstrando tamanha audácia através da transgressão sexual de um relacionamento lésbico.

Em sua conclusão, Daria Cohen nota que os escritores que estuda apresentam o corpo da mulher, por um lado, subjugado pelo olhar e pela atuação masculinos, mas, por outro, também imbuído de resistência aos constrangimentos das normas patriarcais da época. Cohen faz uma recapitulação retomando o "processo de formação da identidade" que os Capítulos de 1 a 3 mostram, ou seja, a tentativa de emergência da moderna subjetividade da mulher que resulta numa atuação mais resoluta no Capítulo 4 . Cohen ressalta que procurou mostrar a "transformação e o progresso" da força da nova subjetividade da mulher na modernidade entre escritores nos quais raramente se espera encontrar tal preocupação.

Como se vê, este estudo traz uma contribuição valiosa, pois ressalta um novo prisma em textos de grandes escritores do modernismo, qual seja, sua sensibilidade com as mudanças socioculturais que tiveram as relações de gênero como um de seus aspectos cruciais. Cohen salienta com cuidado o caráter ambivalente e contraditório da retórica que deixa entrever a 
formação da subjetividade feminina e como textualidade imbricada ao contexto social. Ainda que em alguns pontos repetitivo, dada a reiteração exaustiva da frase "emergência da subjetividade moderna da mulher", bem como um pouco carente do desenvolvimento das teorias que cita entre as páginas 2 e 4 , o livro tem seus méritos. Por salientar com destreza, além dos estratagemas com que os escritores expressaram seus temores quanto ao feminino, também seu próprio reconhecimento do potencial impetuoso das mulheres, a partir do conceito de desejo como cerne da subjetividade moderna, o trabalho de Daria Cohen merece a atenção dos estudiosos do assunto.

Regina R. Félix University of North Carolina Wilmington 